\section{Propagule Type Affects Growth and Fruiting of Uapaca kirkiana, a Priority Indigenous Fruit Tree of Southern Africa}

\author{
Festus K. Akinnifesi, Simon A. Mng'omba ${ }^{1}$, and Gudeta Sileshi \\ World Agroforestry Center (ICRAF), Agroforestry Program, Chitedze \\ Research Station, P.O. Box 30798, Lilongwe 3, Malawi
}

\author{
Thomson G. Chilanga \\ Bvumbwe Agricultural Research Station, P.O. Box 5748, Limbe, Malawi
}

\section{Jarret Mhango}

Mzuzu University, Private Bag 201, Luwinga, Mzuzu 2, Malawi

\section{Oluyede C. Ajayi, Sebastian Chakeredza, Betserai I. Nyoka, and France M.T. Gondwe \\ World Agroforestry Center (ICRAF), Agroforestry Program, Chitedze Research Station, P.O. Box 30798, Lilongwe 3, Malawi}

Additional index words. crown depth, dwarfing, Euphorbiaceae, fruit abortion, fruiting precocity, miombo woodland

\begin{abstract}
One of the limitations of Uapaca kirkiana on-farm cultivation is the long juvenile phase to reach a stable fruiting stage. Marcots and grafts have been identified as feasible and reliable propagation methods for precocious fruiting, but the effects of different propagule types on tree growth and fruit yield have not been evaluated. There is limited knowledge on development and growth forms for trees derived from different propagules. Grafts and marcots were compared with saplings to assess the variability in 1) field growth and fruiting of $U$. kirkiana; and 2) dry matter allocation pattern and tree development models among trees derived from different propagules. Tree development models were used to examine differences among trees from different propagules. The results show that number of branches and fruit load significantly differed between vegetative propagules and saplings, whereas tree height, root collar diameter, crown spread, and fruit size and weight were similar 8 years after establishment. The results suggest differences in intraspecific scaling relationships between height and diameter among propagule sources. Saplings showed a significantly better fit $\left(r^{2}=0.891 ; P<\right.$ $0.0001)$ to the scaling relationship than grafts $\left(r^{2}=0.724 ; P=0.002\right)$ and marcots $\left(r^{2}=\right.$ $0.533 ; P=0.018)$. After 3 years, marcots and grafts started producing fruits. Fruit load was greatest in marcots despite some fruit abortions; thus, marcots had greater fruit yield, early growth, and development and better dry matter allocation.
\end{abstract}

Many indigenous fruit trees (IFTs) of the miombo woodlands of southern Africa are important for the livelihoods of the rural population (Akinnifesi et al., 2008a). This has been shown by market and financial analyses, which have attested that fresh and processed fruit products of IFTs contribute to household income and that women and children are the main beneficiaries (Ramadhani, 2002). IFTs can make a difference in terms

\footnotetext{
Received for publication 18 May 2009. Accepted for publication 18 June 2009.

We thank BMZ and GTZ for providing funds for implementing the project on 'Domestication and Marketing of Indigenous Fruit Trees for Improved Nutrition and Income in southern Africa' and EC and CIDA Canada for providing leveraging funding. ${ }^{1}$ To whom reprint requests should be addressed; e-mailsmngomba@cgiarmw.org.
}

of food security to rural households during periods of food scarcity (Akinnifesi et al., 2008a). Other benefits from the use of IFTs include the biological diversification of farming systems, nutritional security, and employment opportunities (Mithöfer and Waibel, 2008). Integrating and managing IFTs on farmland could be a way to enhance agricultural sustainability through the improvement of fruit and tree traits (Kruise, 2006).

Uapaca kirkiana Müell Arg. belongs to the Euphorbiaceae family and is a priority IFT for domestication in countries of southern Africa (Akinnifesi et al., 2008b). However, U. kirkiana harvest comes from the wild and the lack of knowledge about its vegetative propagation has been a constraint to its domestication (Akinnifesi et al., 2008b; Mng'omba et al., 2007). Vegetative propagation using cuttings, grafting, and layering can capture and fix superior fruit and tree traits and precocious fruiting (Akinnifesi et al., 2006). According to Akinnifesi et al. (2006), fruiting precocity of $U$. kirkiana (fruiting within 2 to 3 years after planting) has been achieved using grafting and layering (marcottage) techniques, whereas saplings start fruiting 10 to 16 years after establishment. This long time to fruiting has been one reason that farmers have been reluctant to cultivate $U$. kirkiana in the past (Ajayi, 2007). The grafting technique is now successful ( $80 \%$ graft take), although this depends on the skill of the grafters, time of the year when scions are collected, and the interval between scion collection and grafting (Akinnifesi et al., 2006, 2008).

Despite the knowledge of vegetative propagation techniques, little is known about the effects of different propagation systems on the partitioning of dry matter in and even on the phenotypic characteristics of the germplasm. Vegetative propagation of physiologically mature trees is generally meant to capture the phenotype and mature phase of the tissues to promote early flowering and fruiting without passing through the juvenile phase.

The development of nonphotosynthetic tissues such as flowers and fruits can have a negative effect on the development of supporting branches (O'Brien et al., 1995), and hence it is expected that allocation of growth resources, biomass, and phenotype is likely to differ among trees derived from different stocks. Trees that allocate fewer resources to supporting stems and trunks per unit growth height should grow faster than those that allocate more (O'Brien et al., 1995). The tradeoff is on survival: self-supporting plants that allocate too little to stems may buckle under their own mass or break as a result of wind stress or other loads (O'Brien et al., 1995).

A phenotype is a constellation of biological traits such as photosynthetic area $(A s)$, stem radius $\left(r_{0}\right)$, height or plant length $(L)$, and whole plant mass $(M)$ that often covary with each other during ontogeny through some scaling relationship (Niklas, 1993; Price et al., 2007). According to Price et al. (2007), each relationship can be expressed in terms of continuous traits dependent on network geometry as follows:

$$
\begin{aligned}
A_{s} & \propto M^{\theta} ; r_{0} \propto M^{a \theta} ; L \propto M^{b \theta} ; L \propto r_{0}^{b / a} ; \\
A_{s} & \propto r_{0}^{1 / a} ; A_{s} \propto L^{1 / b}
\end{aligned}
$$

where $a$ and $b$ are parameters that characterize the geometry of the vascular networks in a given species and $\theta$ is the scaling exponent, and it is equal to $1 /(2 a+b)$.

Several hydrodynamic and anatomical attributes of plant hydraulics and branching morphology are determined by $\theta$ (Enquist et al., 2007; West et al., 1999). West et al. (1997, 1999) hypothesized that the value of $\theta$ arises from the geometry of vascular networks and resource exchange surfaces. The core assumption of this theory is that many organismal, anatomical, and physiological traits are linked mechanistically by allometric scaling of the vascular network (Price et al., 2007; West et al., 1999). The 
scaling of the height of dicotyledonous trees has been examined principally in terms of elastic and stress similarity models (Niklas, 1993). The elastic similarity model assumes that the deflection at the free end of a support member remains constant relative to the length or height $(H)$. This assumption requires $H$ to scale to diameter $(d)$ as follows:

$$
H \propto d^{2 / 3}
$$

The stress similarity model is based on the assumption that a constant maximum stress level exists throughout the length of columnar tree trunks. This assumption requires $H$ to scale to $d$ as follows (Niklas, 1993):

$$
H \propto d^{1 / 2}
$$

Therefore, we hypothesized that marcots and grafted trees will not conform to the optimizing assumptions underlying the scaling relationships proposed for naturally growing trees (Price et al., 2007; West et al., 1999) in a similar manner.

We expected saplings to be taller than grafts or marcots within the first 5 years of establishment and that marcots to fruit earlier than grafts. The objectives of this study were to 1 ) assess growth and fruiting of $U$. kirkiana derived from marcots, grafts, and saplings; and 2) to determine whether allocation pattern and models of tree development differ among trees derived from different propagule types.

\section{Materials and Methods}

Site description. The study site was ICRAFMakoka Research Station in Malawi (lat. $15^{\circ} 30^{\prime} \mathrm{S}$ and long. $35^{\circ} 15^{\prime} \mathrm{E}$ ). This station lies $1029 \mathrm{~m}$ above sea level and has unimodal rainfall with an annual range of 560 to $1600 \mathrm{~mm}$. Temperature varies between 16 and $32{ }^{\circ} \mathrm{C}$ (Akinnifesi et al., 2004). The soils at the station are Ferric Lixisol and texture is $46 \%$ sand, $46 \%$ clay, and 8\% silt (Akinnifesi et al., 2008a).

Plant material and techniques. A Uapaca kirkiana fruit orchard was established from marcottage (air layering), grafted, and sapling stocks in 2001. For marcots (i.e., rooting tree stems, while they are attached to a mother tree), stems were ring-barked and the growing medium was wrapped around the wound for root induction. The marcots were set on female $U$. kirkiana trees already in production at Govala forest woodland in Zomba district, but their ages were unknown. Because trees were tall, ladders were used to reach shoots (approximately up to threefourths of tree height) and set marcots. Shoots were selected on tertiary branches, measuring $\approx 30 \mathrm{~cm}$ from the shoot tip. The diameters of the shoots were 10 to $15 \mathrm{~mm}$. A girdle (25 $\mathrm{mm}$ long) was made around each U. kirkiana shoot of the previous year's growth. The marcots were set in Apr., Aug. and Dec. 1999. They were all harvested at the same time and successful marcots were detached from mother trees and planted into polythene pots filled with a mixture of sand and forest soils (1:3). The forest soil was collected under U. kirkiana trees to provide mycorrhizal inoculum. The marcots were kept in the nursery for 8 months before planting them in the field.

Whip grafting was done when $U$. kirkiana seedling rootstocks were 2 years old and $\approx 10$ $\mathrm{mm}$ (diameter) and 40 to $60 \mathrm{~cm}$ tall. Seeds were collected from different trees in Phalombe forest woodland (lat. $16^{\circ} 09^{\prime} \mathrm{S}$, long. $34^{\circ} 29^{\prime}$ E, $1260 \mathrm{~m}$ above sea level) and sown to raise seedlings. Some of seedlings were used as rootstocks for the grafted plants, and hence the seedling rootstocks and saplings were of the same age and origin (Phalombe provenance). Scions ( $\approx 1$ to 2 years old) were collected from the forest woodland in Zomba (Zomba provenance). This provenance was selected for scion collection because of its proximity to the study site. The scions and the marcots were from Zomba provenance, but not necessarily from the same trees. Therefore, we hypothesized that if there was no provenance difference, if any, then it has an insignificant influence on early growth of the planting materials. Any difference in growth would be as a result of propagule effect rather than provenance effect. The saplings and grafts were raised in a nursery for 18 months. These and the marcots were planted at the same time.

The fruit orchard comprised marcots, grafts, and saplings (treatments), but because of high tree mortality, only a total of $36 U$. kirkiana trees were evaluated in this study. The experiment was laid out in a randomized block design with 12 trees per treatment and three replications $(3 \times 3 \times 4)$. Tree row orientation was north-south to maximize light use. Marcotted and grafted trees were planted at $6 \mathrm{~m} \times 6-\mathrm{m}$ spacing, whereas saplings were planted at $5 \mathrm{~m} \times 5 \mathrm{~m}$. All trees were planted in Jan. 2001 in $60 \mathrm{~cm} \times 60-\mathrm{cm}$ deep holes. Weeding was done twice a year using hand hoes. Trees were rain-fed except for the dry season during the first year of establishment when irrigation was administered at $\approx 15 \mathrm{~L}$ per tree and per week. This irrigation continued for 4 months.

Data collection. Fruit yield and tree growth data were collected from Jan. 2001 (initial measurements) to July 2008. Number of fruits produced per tree for each treatment (marcots, grafts, or saplings) was counted every month from fruit induction through to ripening. Initial tree height and branching and root collar diameter were measured at planting. Thereafter, these variables and including bole height, crown depth, and spread were recorded every 3 months.

Data analyses. Continuous data such as tree height, root collar diameter, diameter at breadth height, crown depth, and spread were analyzed using a linear mixed model. Propagule type was used as the fixed effect and individual trees were used as the random effect in the model. Fruit yield was analyzed using generalized linear model (GLM) assuming negative binomial error distribution of fruit counts. In the GLM, the effects of propagule type, branch type, and their interactions were entered, and the model fit was examined using the deviance and likelihood ratio statistics. Because inclusion of the interaction term did not improve model fit and parsimony, only the main effects were analyzed. In all cases, statistical inference was based on the $95 \%$ confidence intervals of parameter estimates rather than post hoc test statistics. This is because the $95 \%$ confidence interval functions as a very conservative test of hypothesis that attaches a measure of accuracy to sample statistics (Sim and Reid, 1999).

We considered models for the scaling of tree height $(H)$ with stem diameter $(d)$ in various treatments. An agreement between observed $H$ and fitted $H$ using different models (Eqs. 2 and 3 ) across the whole range of mean diameters was graphically evaluated. This was done by plotting $H$ values against respective $d$ values. This agreement was statistically tested using least square linear regression of observed values against fitted values (used as independent variable). This method was found to be more robust than testing model fit with regression of fitted against the observed. If the model under consideration predicts $H$ from $d$ consistently, the resulting regression line will have a constant slope $(\beta=1)$. If it predicts $H$ without bias, the regression line will have zero intercept $(\alpha=0)$. Model fit was evaluated using the $R^{2}$ and predicted residual sum of squares (PRESS). The smaller the PRESS value, the better is the agreement between the observed and predicted values.

\section{Results}

Tree growth parameters. In this study, all the marcots rooted synchronously by Apr. 2000 , although they were set in different months. Five years after establishment, saplings were significantly $(P \leq 0.05)$ taller than grafted trees (Table 1). Saplings also had significantly bigger root collar diameters than marcots and marcots had significantly more number of tertiary branches than saplings and grafted trees. No significant differences $(P>$ 0.05 ) were observed in number of primary branches, secondary branches, crown spread, or bole height (Table 1). After 8 years of field establishment, no difference was found between propagule types except in the number of primary, secondary, and tertiary branches (Table 2), where marcots and grafts had more branches than saplings.

A general trend shows that in the first 5 years of establishment, saplings showed a steep increase in height (Fig. 1A). However, after 8 years of establishment, no significant differences were obtained among saplings, marcots, and grafted trees in height. For root collar diameter, a similar trend was obtained (Fig. 1B). A general trend shows that marcots and grafted trees had smaller bole height than saplings (Tables 1 and 2).

The intrapropagule scaling relationships between tree height and diameter are presented in Figure 2. Saplings had a significantly better fit $\left(r^{2}=0.891 ; P<0.0001\right)$ to the hypothesized scaling relationship than grafted trees $\left(r^{2}=0.724 ; P=0.002\right)$ and 
Table 1. Relative growth parameters for Uapaca kirkiana derived from grafts, marcots, and saplings 5 years after establishment (2005) at ICRAF-Makoka fruit tree orchard. ${ }^{\mathrm{z}}$

\begin{tabular}{lcrrc}
\hline Growth parameter & \multicolumn{1}{c}{ Marcots } & \multicolumn{1}{c}{ Grafts } & \multicolumn{1}{c}{ Saplings } & Probability \\
\hline Tree height $(\mathrm{m})$ & $2.4 \pm 0.11$ & $2.0 \pm 0.13$ & $2.7 \pm 0.14$ & $<0.05$ \\
Bole height $(\mathrm{m})$ & $0.39 \pm 0.04$ & $0.35 \pm 0.04$ & $0.46 \pm 0.64$ & NS \\
Root collar diameter $(\mathrm{cm})$ & $8.50 \pm 0.32$ & $9.14 \pm 0.35$ & $10.3 \pm 0.36$ & $<0.05$ \\
Crown depth (m) & $2.0 \pm 0.13$ & $3.5 \pm 0.04$ & $2.4 \pm 0.76$ & $<0.05$ \\
Crown spread (m) & $2.7 \pm 0.14$ & $2.3 \pm 0.13$ & $2.4 \pm 0.16$ & NS \\
No. of primary branches & $17.2 \pm 1.33$ & $15.8 \pm 0.95$ & $15.3 \pm 2.00$ & NS \\
No. of secondary branches & $25.0 \pm 2.60$ & $19.9 \pm 2.60$ & $15.3 \pm 2.00$ & NS \\
No. of tertiary branches & $15.0 \pm 2.97$ & $10.3 \pm 2.91$ & $5.6 \pm 1.32$ & $<0.05$ \\
Mean number of fruits & 78 & 52 & 0 &
\end{tabular}

${ }^{\mathrm{z} M e a n s} \pm \mathrm{SE}$.

NS $=$ Means are not significantly different from each other within a row at $\alpha=0.05$.

Table 2. Relative growth parameters for Uapaca kirkiana derived from grafts, marcots, and saplings 8 years (2008) after field establishment at ICRAF-Makoka fruit tree orchard. ${ }^{\mathrm{z}}$

\begin{tabular}{lcccc}
\hline Growth parameter & Marcots & Grafts & Seedling stock & Probability \\
\hline Tree height $(\mathrm{m})$ & $3.8 \pm 0.14$ & $3.5 \pm 0.17$ & $3.6 \pm 0.27$ & NS \\
Bole height $(\mathrm{m})$ & $0.41 \pm 0.06$ & $0.32 \pm 0.04$ & $0.61 \pm 0.09$ & NS \\
Root collar diameter $(\mathrm{cm})$ & $12.7 \pm 0.5$ & $11.4 \pm 0.6$ & $11.3 \pm 1.1$ & NS \\
Crown depth (m) & $3.3 \pm 0.13$ & $3.2 \pm 0.15$ & $2.9 \pm 0.31$ & NS \\
Crown spread (m) & $3.8 \pm 0.23$ & $3.1 \pm 0.18$ & $2.8 \pm 0.35$ & NS \\
No. of primary branches & $19.4 \pm 1.5$ & $22.8 \pm 1.2$ & $15.3 \pm 1.7$ & $<0.05$ \\
No. of secondary branches & $42.0 \pm 4.6$ & $30.3 \pm 2.5$ & $19.6 \pm 4.2$ & $<0.05$ \\
No. of tertiary branches & $36.4 \pm 4.1$ & $20.3 \pm 2.6$ & $8.1 \pm 2.7$ & $<0.05$ \\
Fresh fruit weight $(\mathrm{g})$ & $13.0 \pm 0.35$ & $12.2 \pm 0.28$ & - & NS \\
Fruit length $(\mathrm{cm})$ & $3.1 \pm 0.03$ & $2.8 \pm 0.06$ & - & NS \\
Fruit diameter $(\mathrm{cm})$ & $2.84 \pm 0.03$ & $2.77 \pm 0.06$ & - & NS \\
\hline
\end{tabular}

${ }^{\mathrm{z} M e a n s} \pm \mathrm{SE}$.

NS $=$ Means are not significantly different from each other at $\alpha=0.05$
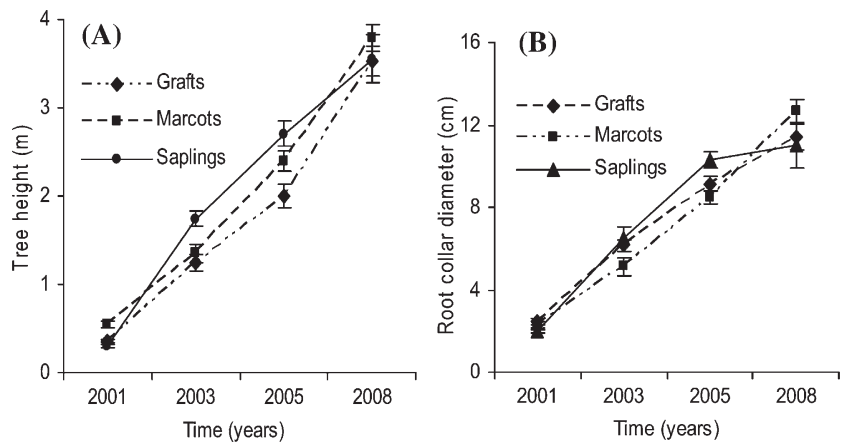

Fig. 1. Variation in (A) tree height $(\mathrm{m})$ and $(\mathbf{B})$ root collar diameter $(\mathrm{cm})$ of Uapaca kirkiana with propagule type during 8 years at ICRAF-Makoka fruit orchard in Malawi. Vertical bars represent SE of means.

marcots $\left(r^{2}=0.533 ; P=0.018\right)$. The $95 \%$ confidence intervals of the slopes also show that marcots had wider variability than grafted trees and saplings. The elastic similarity model (Table 3 ) fitted the data for the saplings better $\left(r^{2}=0.862\right)$ than the stress similarity model $\left(r^{2}=0.852\right)$. Similarly, in the case of grafted trees, the elastic similarity model was better than the stress similarity model. The $95 \%$ confidence intervals of the intercepts indicate that the elastic similarity model predicted $H$ without significant bias $(\alpha=0)$ in grafted trees. The stress similarity models predicted $H$ with significant bias $(\alpha>$ $0)$ and inconsistency $(\beta>1)$ in grafted trees. Both models poorly fitted the data for marcots (Table 3; Fig. 3) and explained less than $50 \%$ of variation between observed and predicted height and with significant bias $(\alpha>0)$ and inconsistency $(\beta>1)$.
Fruit yield. Significant differences were obtained in fruit load in the early years of production (Table 1), but no significant differences $(P>0.05)$ in fresh fruit weight, fruit length, and diameter (Table 2) were obtained after 8 years. Marcots and grafted trees produced fruits, but none of the saplings did after 8 years of establishment. Marcots (Fig. 4A) had significantly higher fruit load than grafted trees throughout the fruit production season (from fruit set to fruit ripening). A heavy fruit drop (abortion) occurred in April and fruit retention was stabilized in May for both marcots and grafted trees (Fig. 4A).

Fruit yield significantly differed with treatments $(P<0.0001)$ and branch type $(P<0.0228)$ after 8 years of establishment. For marcots and grafted trees, there were significantly more fruits on secondary and tertiary branches than on the other branch types. Furthermore, marcots had more fruits per branch than grafted trees (Fig. 4B), but a few fruits were produced on main stems (leading stem).

\section{Discussion}

In this study, marcots and grafts differ from saplings in branching characteristics and capacity to produce fruits. Scions could be younger than rootstocks but mature with respect to ontogenetic ageing. The grafts expressed reduced maturity (fewer fruits, secondary and tertiary branching) compared with marcots. This could be attributed to the fact that marcots were mature tissues on their own roots and grafts were mature tissues on juvenile roots, whereas saplings were juvenile plants on seedling roots. Therefore, the rootstocks somehow rejuvenated the scions.

The overall tree growth shows no differences in height, crown depth, and root collar diameter for the three different propagule types. This could be attributed to the effects of environment and scion/rootstock combinations. Scions and marcottage were from the same provenance (Zomba), whereas rootstocks and saplings were from Phalombe. A decrease in number of tertiary branches, especially for saplings, could reduce the foliage and dry matter production and this negatively affected tree height, crown spread and width, and root collar diameter as shown in Table 2. This could explain why saplings were not taller than grafts as expected. In this study, it is likely that rootstocks did not induce dwarfing effect on the grafted trees, but this might be clear at a later stage.

Marcots possess lateral roots, but not the main root, and hence the roots might not have the same depth or spread as grafts or saplings. Increase in growth of lateral roots could be an adaptation mechanism to strengthen anchorage and water uptake. This could increase shoot growth, and hence tree height was similar to grafts and saplings. However, we expected the marcots to have the least capacity to adapt to harsh environments. Some marcots were set on the lower tree branches and considering tree ontogenetic ageing, lower branches are more juvenile than the upper branches. Possibly, marcots set on lower tree branches could be vigorous and this could explain why they were tall. However, further investigation is needed to verify this possibility. Apart from differences in shoot ontogeny, it is possible that marcots had more carbohydrate reserves than other two propagule types. However, this was not measured. According to Akinnifesi et al. (2008b), U. kirkiana marcots were often bigger than grafts.

Marcots appear to show wider plasticity, thus departing from the constraints set by scaling relationships. In ecological terms, this wider variability is advantageous to trees in terms of wind resistance, capturing solar radiation, and pest and disease risks. 

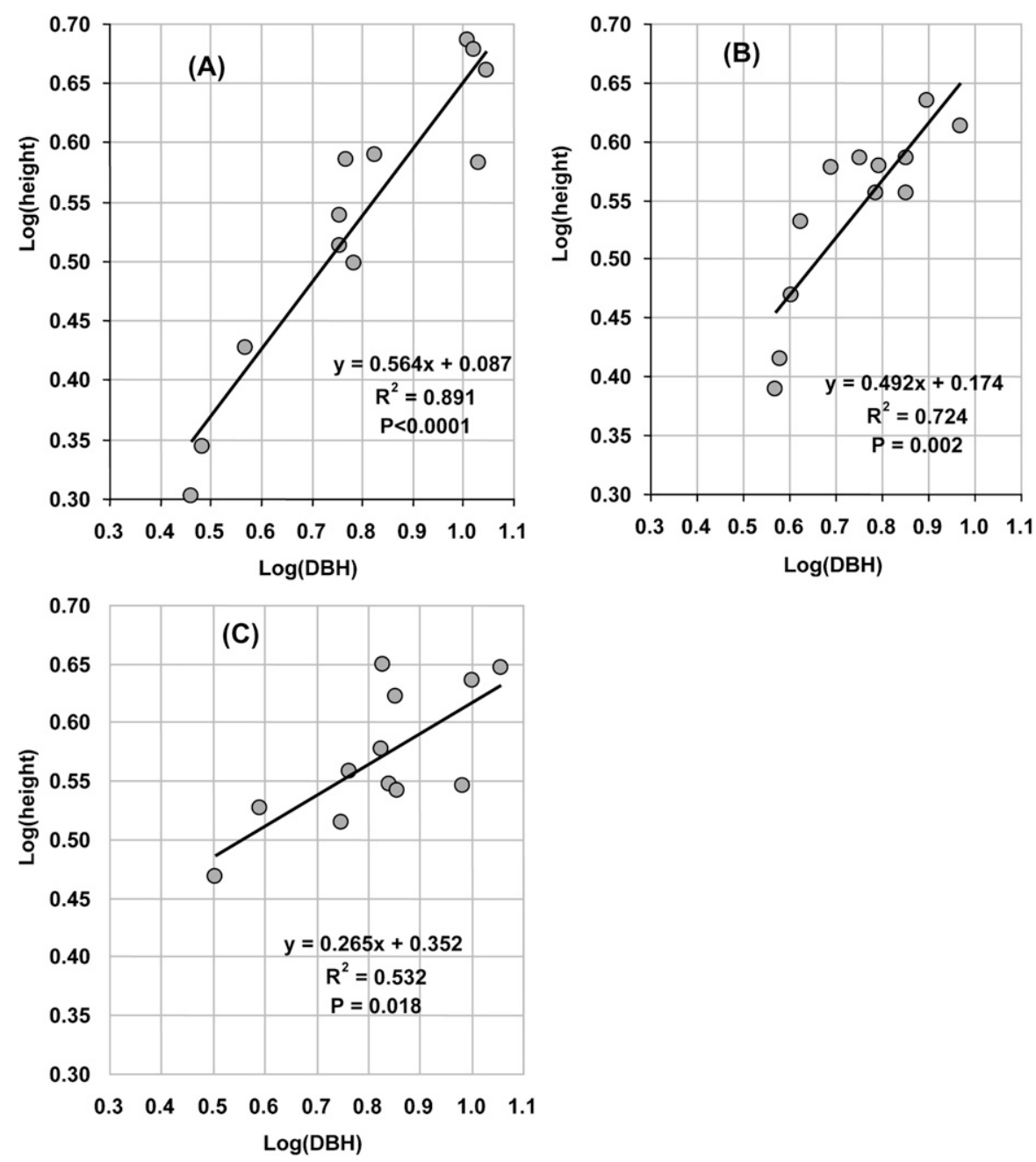

Fig. 2. Scaling of plant height with diameter in Uapaca kirkiana plants raised from (A) seedling stock, (B) grafted stock, and $(\mathbf{C})$ marcots.

Table 3. Statistical tests of the agreement between the observed and fitted values of height assuming the elastic and stress similarity models for the three Uapaca kirkiana propagule sources.

\begin{tabular}{lllcccr}
\hline $\begin{array}{l}\text { Propagule } \\
\text { source }\end{array}$ & \multicolumn{1}{c}{ Model } & \multicolumn{1}{c}{ Intercept $(\alpha)^{\mathrm{z}}$} & \multicolumn{1}{c}{ Slope $(\beta)^{\mathrm{z}}$} & PRESS & $R^{2}$ & $P$ value \\
\hline Saplings & Elastic similarity & $0.22(-1.18,0.74)$ & $1.48(-2.16,3.64)$ & 2.00 & 0.862 & $<0.0001$ \\
& Stress similarity & $0.70(-0.06,1.46)$ & $0.81(-0.12,3.05)$ & 2.16 & 0.852 & $<0.0001$ \\
Grafts & Elastic similarity & $0.34(-0.91,1.59)$ & $1.34(-1.03,4.22)$ & 1.60 & 0.716 & 0.0005 \\
& Stress similarity & $1.15(0.17,2.13)$ & $0.74(0.68,3.58)$ & 1.67 & 0.705 & 0.0006 \\
Marcots & Elastic similarity & $1.75(0.50,3.00)$ & $0.76(1.51,4.49)$ & 1.83 & 0.496 & 0.0105 \\
& Stress similarity & $2.24(1.26,3.22)$ & $0.42(2.40,4.04)$ & 1.85 & 0.491 & 0.0112 \\
\hline
\end{tabular}

${ }^{2}$ Figures in parentheses are the $95 \%$ confidence intervals.

The wider variability exhibited by marcots could be that they were set on different trees from the same provenance, but their ages could not be established. Mwase et al. (2006) reported that most genetic variation $(90.8 \%)$ was within provenances but less $(8.2 \%)$ among provenances of $U$. kirkiana. However, they reported low variation in growth and morphological traits among seed sources. This could explain the reason that saplings showed a better fit of model than marcots and grafts. This intrapopulation variation and differences in shoot ontogenetic ageing could explain plasticity of the marcots.
U. kirkiana is dioecious, and hence zygotic embryos from a single mother tree are not identical. That is probably why a wide variation was observed among seedlings. Although this could play an important role in regulating tree height, scion/rootstock combination and environmental conditions could be overriding factors.

From this study, secondary and tertiary branches were more productive than the rest of the branches. However, the trees were not subjected to other horticultural practices such as pruning or other forms of training, which could control tree height and canopy growth structure. This could optimize fruit yield by reducing fruit drop because lower or optimal number of branches are maintained per tree. A general trend shows reduction in bole height for vegetative propagated trees and this meant early branching unlike saplings. Perhaps, differences in bole height may be clear as marcots, grafts, and saplings grow older.

In this study, overproduction of fruits was corrected by fruit abortion, which is a physiological phenomenon that occurs in many fruit trees to reduce fruit-fruit competition. According to Grossman and DeJong (1995), maximum organ growth potential is genetically determined and attained under optimal environmental conditions. A heavy fruit load can allocate few resources to support growth and development of young fruits. Mohana et al. (2001) reported that genetic relatedness among Dalbergia sissoo seeds determined intrafruit seed competition, which caused seed abortion. This competition was less among the genetically related Dalbergia sissoo seeds. In this study, fruit abortion was observed from the second month after fruit set and marcots had the highest fruit abortion, unlike grafts. Although the marcots had the highest fruit abortion, their final fruit load was still higher than the grafts. The marcots and grafts stabilized fruit retention 3 months (May) after the onset of fruiting.

The greater number of fruit produced by marcots could be attributed to a higher number of secondary and tertiary branches, unlike grafted trees. No differences between marcots and grafts were found in terms of individual fresh fruit weight. Akinnifesi et al. (2006) reported that some $U$. kirkiana could produce up to 6000 fruits per tree and with fruit size of $\approx 3$ to $4 \mathrm{~cm}$ in diameter, but such trees are well-established and attained fruiting stability. In this study, marcots produced some individual fruits, which were more than $3.5 \mathrm{~cm}$ in diameter. Possibly, they just started stabilizing fruit retention earlier than grafted trees, although not completely stable.

This study is useful, particularly to tree propagators and nurserymen as they select propagation techniques for a particular fruit tree (Mng' omba et al., 2008). In this case, the effect of different propagule types on field performance of fruit trees could be established. Tree propagators often use routine methods with the lowest risk of failure. However, there is little consideration on field performance and management of fruit trees considering that each propagation technique has positive and negative effects on field performance and management (Mng'omba et al., 2008). In this study, marcots have exhibited the best field performance with respect to fruit yield within 8 years of establishment. This study contributes to decision-making when choosing any particular propagation method to use for a specific fruit tree.

In conclusion, $U$. kirkiana marcots were superior in fruit production and most crown architecture (crown spread and number of 

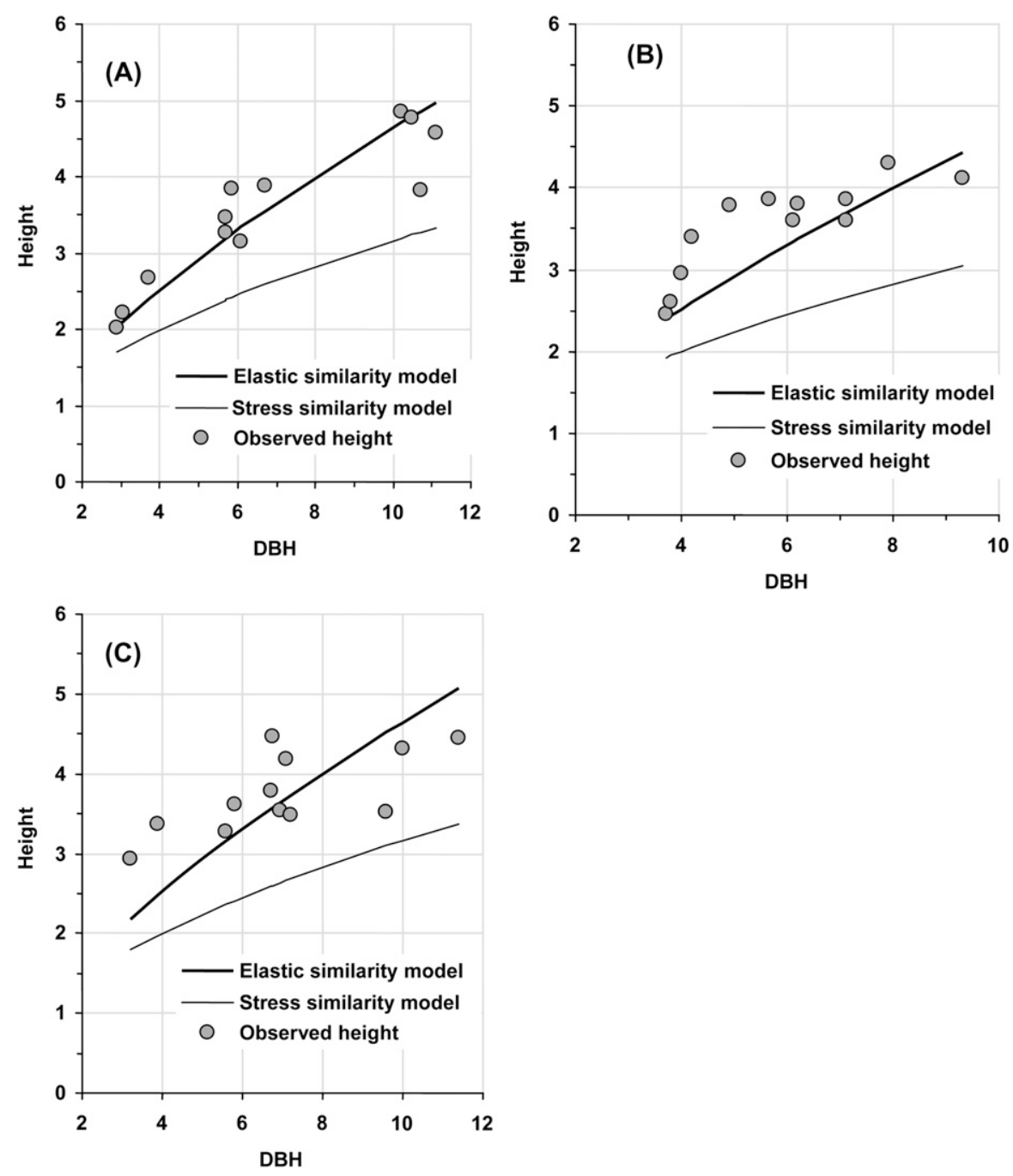

Fig. 3. Variation in the height to diameter scaling relationships of Uapaca kirkiana plants raised from (A) seedling stock, (B) grafted stock, and (C) marcots. Smooth lines indicate the height predicted assuming the elastic and stress similarity models.
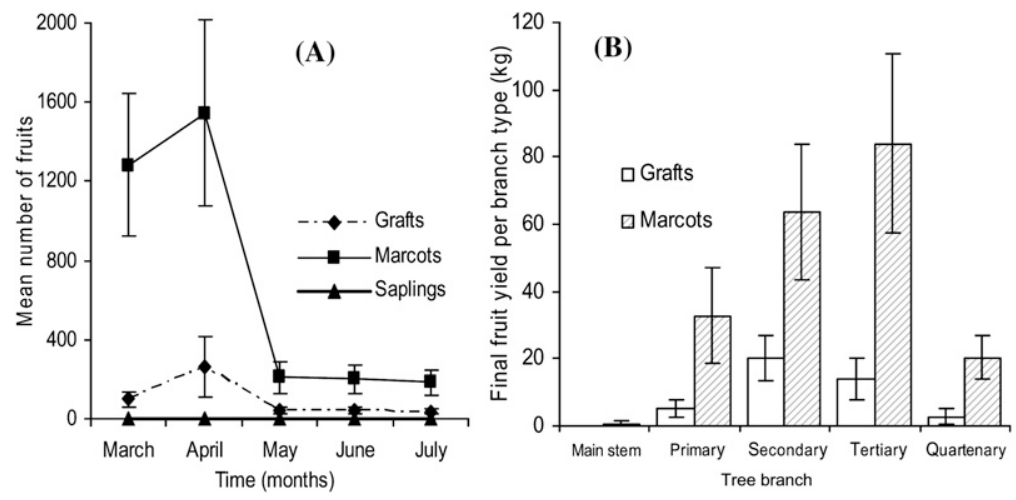

Fig. 4. Variation of Uapaca kirkiana in (A) fruit abundance during 2008 fruit production season and (B) fruit yield per branch 8 years after establishment at Makoka in Malawi. Fruit yield significantly differed with propagule type $(P<0.0001)$ and branch type $(P=0.0228)$. Vertical bars represent SE of means.

branches) 8 years after establishment and hence the best of the three propagation methods for $U$. kirkiana. Marcotting and grafting are good propagation techniques to capture superior phenotype of superior trees. Stress and elastic similarity models poorly fitted the data for marcots, an indication of wide population variation. There was no dwarfing effect for the three propagule types, but selection of dwarfing rootstocks would be important to reduce fruit damage during harvesting.

\section{Literature Cited}

Ajayi, O.C. 2007. User acceptability of soil fertility management technologies: Lessons from farmers' knowledge, attitude and practices in southern Africa. J. Sustain. Agr. 30:21-40.

Akinnifesi, F.K., F.R. Kwesiga, J. Mhango, T. Chilanga, A. Mkonda, C.A.C. Kadu, I. Kadzere, D. Mithöfer, J.D.K. Saka, G. Sileshi, T. Ramadhani, and P. Dhliwayo. 2006. Towards the development of miombo fruit trees as commercial tree crops in southern Africa. forests. Trees and Livelihoods 16:103-121.

Akinnifesi, F.K., F.R. Kwesiga, J. Mhango, A. Mkonda, T. Chilanga, and R. Swai. 2004. Domesticating priority for Miombo indigenous fruit trees as a promising livelihood option for small-holder farmers in southern Africa. Acta Hort. 632:15-30.

Akinnifesi, F.K., J. Mhango, G. Sileshi, and T. Chilanga. 2008a. Early growth and survival of three miombo indigenous fruit tree species under fertilizer, manure and dry-season irrigation in southern Malawi. For. Ecol. Mgt. 255:546-557.

Akinnifesi, F.K., O.C. Ajayi, G. Sileshi, P. Matakala, F.R. Kwesiga, C. Ham, I. Kadzere, J. Mhango, S.A. Mng'omba, T. Chilanga, and A. Mkonda. 2008b. Creating opportunities for domestication and commercializing miombo indigenous fruit trees in southern Africa, p. 137-170. In: Akinnifesi, F.K., R.R.B. Leakey, O.C. Ajayi, G. Sileshi, Z. Tchoundjeu, P. Matakala, and F.R. Kwesiga (eds.). Indigenous fruit trees in the tropics: Domestication, utilization and commercialization. World Agroforestry Center: Nairobi. CAB International Publishing, Wallingford, UK.

Enquist, B.J., A.P. Allen, J.H. Brown, A.J. Kerkhoff, K.J. Niklas, C.A. Price, and G.B. West. 2007. Biological scaling: Does the exception prove the rule? Nature 445:E9-E10.

Grossman, Y.L. and T.M. DeJong. 1995. Maximum fruit growth potential following resource limitation during peach growth. Ann. Bot. (Lond.) 75:561-567.

Kruise, T. 2006. Economics of in-situ conservation of indigenous trees: The case of smallholder farmers in central Malawi. MSc Thesis, University of Hannover, Hannover, Germany.

Mithöfer, D. and H. Waibel. 2008. Economics of on-farm production of indigenous fruits, $\mathrm{p}$. 237-253. In: Akinnifesi, F.K., R.R.B. Leakey, O.C. Ajayi, G. Sileshi, Z. Tchoundjeu, P. Matakala, and F.R. Kwesiga (eds.). Indigenous fruit trees in the tropics: Domestication, utilization and commercialization. World Agroforestry Center: Nairobi. CAB International Publishing, Wallingford, UK.

Mohana, G.S., R.U. Shaanker, K.N. Ganeshaiah, and S. Dayanandan. 2001. Genetic relatedness among developing seeds and intra fruit seed abortion in Dalbergia sissoo (Fabaceae). Amer. J. Bot. 88:1181-1188.

Mng'omba, S.A., F.K. Akinnifesi, G. Sileshi, O.C. Ajayi, S. Chakeredza, and W.F. Mwase. 2008. A decision support tool for propagating Miombo indigenous fruit trees of southern Africa. Afr. J. Biotechnol. 7:4677-4686.

Mng'omba, S.A., E.S. du Toit, F.K. Akinnifesi, and H.M. Venter. 2007. Histological evaluation of early graft compatibility in Uapaca kirkiana Muell Arg. scion/stock combinations. HortScience 42:1-5.

Mwase, W.F., A. Bjørnstad, B. Stedje, J.M. Bokosi, and M.B. Kwapata. 2006. Genetic diversity of Uapaca kirkiana Müell. Årg. populations as revealed by amplified fragment length 
polymorphisms (AFLPs). Afr. J. Biotechnol. 5: 1205-1213.

Niklas, K.J. 1993. The scaling of plant height: A comparison among major plant clades and anatomical grades. Ann. Bot. (Lond.) 72:165172.

O’Brien, S.T., S.P. Hubbell, P. Spiro, R. Condit, and R.B. Foster. 1995. Diameters, height, crown, and age relationships in eight neo- tropical tree species. Ecology 76:19261939.

Price, C.A., B.J. Enquist, and V.M. Savage. 2007. A general model for allometric covariation in botanical form and function. Proc. Natl. Acad. Sci. USA 104:13204-13209.

Ramadhani, T. 2002. Marketing of indigenous fruits in Zimbabwe. Socio-economic Studies on Rural Development. Vol. 129. Wissenschaftsverlag Vauk, Kiel, Germany.
Sim, J. and N. Reid. 1999. Statistical inference by confidence intervals: Issues of interpretation and utilization. Phys. Ther. 79:186-195.

West, G.B., J.H. Brown, and B.J. Enquist. 1997. A general model for the origin of allometric scaling laws in biology. Science 276:122126.

West, G.B., J.H. Brown, and B.J. Enquist. 1999. A general model for the structure and allometry of vascular systems. Nature 400:664-667. 